\title{
Учебно-методическая работа
}

УДК 001:331.102.312:621

\section{Основные направления технического творчества в инженерном образовании}

\author{
И.С. Потапцев, В.В. Бушуева, Н.Н. Бушуев \\ МГТУ им. Н.Э. Баумана, 105005, Москва, Российская Федерация, 2-я Бауманская ул., д. 5, стр. 1.
}

\section{The main trends of technical creativity in engineering education}

\author{
I.S. Potaptsev, V.V. Bushueva, N.N. Bushuev \\ Bauman Moscow State Technical University, building 1, 2-nd Baumanskaya str., 5, 105005, Moscow, Russian Federation. \\ e-mail: isp1939@mail.ru,vbysh2008@rambler.ru, agrohim1@rambler.ru
}

В настоящее время актуальна систематизация основных направлений технического творчества, необходимых в инженерном образовании. Приведен краткий обзор применения форм технического творчества в МГТУ им. Н.Э. Баумана, показана необходимость активизировать данное направление. Разработаны структурные схемы технического творчества и формы его организации. Предложено целостное представление отдельных разрозненных видов технического творчества и форм его организации в техническом университете, что представляет определенную новизну. Основные составные элементы технического творчества рассмотрены в единстве и взаимосвязи. В научной и методической литературе такой подход, выражающий целостность технического творчества, не описывается. Его значимость заключается в координирующей и ориентирующей функции. Предложены рекомендации по применению принципов технического творчества и форм организации в работе со студентами; приведено соотношение форм активизации технического творчества в отечественной и зарубежной практике, показаны их достоинства и недостатки. Обоснована необходимость формирования практических навыков технического творчества на всех стадиях подготовки будущих инженеров и рекомендовано создание в университете единого центра организации и управления различными видами технического творчества.

Ключевые слова: техническое творчество, практические навыки, принципы технического творчества, единый центр организации и управления основными видами технического творчества.

The main trends of technical creativity in engineering education need to be systematized. A brief review of the forms of technical creativity at Bauman Moscow State Technical University is presented, and the importance of this activity is proved. The block diagrams of the technical creativity organizational forms are developed. A new unified representation of specific types of technical creativity and its organizational forms in a technical university is proposed. The main components of technical creativity are considered to be united and dependent on one another. Such an approach expressing the integrity of technical creativity is not represented in the scientific and methodological literature. However, it is very important due to its coordinating and orienting functions. This paper suggests the principles of technical creativity and the forms of its organization to be used while working with students. The forms of technical creativity in 
domestic and foreign practices are described along with their advantages and disadvantages. The importance of developing practical technical creativity skills at all stages of preparation of future engineers is proved. It is recommended that a united center for the organization and management of the main types of technical creativity should be set up at the University.

Keywords: technical creativity, skills, principles of technical creativity, united center for the organization and management of the main types of technical creativity.

В настоящее время социальный заказ направлен на творческих специалистов, способных создавать новую технику. При современных темпах развития науки и техники, частой смене технологий и производственных процессов, наличии информационных технологий требуется постоянный профессиональный рост. Старые знания и навыки быстро меняются, требуются новые нестандартные, альтернативные решения, новое применение функционирования того или иного технического объекта. В условиях инновационной экономики значимой является проблема подготовки инженеров с ориентацией на творческие навыки, что обусловливает внедрение в учебный процесс элементов технического творчества и форм его организации.

В МГТУ им. Н.Э. Баумана техническому творчеству всегда уделялось значительное внимание, в частности, были организованы спецкурсы по техническому творчеству, студенческие кружки, студенческое проектно-конструкторское бюро (СПКБ), методические семинары на кафедрах, конференции и т.д. Некоторые сотрудники еще помнят семинар по техническому творчеству для преподавателей, которым руководил академик РАН К.С. Колесников.

Со временем техническому творчеству стало меньше уделяться внимания. Например, СПКБ, которое было достаточно результативно, сегодня не функционирует, прекращены и многие другие формы работ. В тоже время появились новые, интересные и значимые направления, например, участие студентов старших курсов в выполнении хоздоговорных и госбюджетных НИОКР. Эти работы сегодня ведут почти все кафедры университета. Однако современные условия диктуют необходимость активизации работы по техническому творчеству таким образом, чтобы техническое творчество проходило через все звенья подготовки будущего инженера с учетом современных условий и возможностей.

Цель работы - систематизировать, представить в единой структуре, взаимосвязи, преемственности разрозненные, отдельные виды работ по техническому творчеству и форм его организации.

Рассмотренные в статье виды технического творчества охватывают все стадии подготовки будущего инженера. Такой подход, т. е. целостное представление всех звеньев в единой системе, в методическом плане имеет определенную новизну. В научной и методической литературе подобная общая систематизация технического творчества и форм его организации отсутствует, рассматриваются лишь те или иные отдельные звенья и не всегда во взаимосвязи и взаимодействии. Значение предлагаемого целостного представления, объединяющего все основные виды работ технического творчества, заключается в координирующей, ориентирующей функции.

В современной научной литературе понятие «техническое творчество» употребляется лишь в том случае, когда речь идет о разработке технических систем. В остальных случаях используется понятие «инженерное творчество», которое значительно шире по содержанию. Это объясняется тем, что современная инженерная деятельность включает много видов работ: исполнительную, организаторскую, конструкторскую, технологическую и др. Однако основным направлением деятельности инженера является создание, совершенствование, развитие технических систем, технологий, поиск новых технических идей и решений. И в этом плане понятия «инженерное творчество» и «техническое творчество» совпадают.

Основные виды деятельности технического творчества и его структуру можно представить в виде схемы, приведенной на рис. 1. В данной схеме обобщен опыт инженерной деятельности, а также учтены наиболее значимые моменты учебного процесса в техническом университете. Несомненно, схему можно уточнять, дополнять, корректировать в соответствии со спецификой различных отраслей, т. е. совершенствовать.

Наиболее значимые структурные звенья общей схемы, представленной на рис. 1, рассмотрены более подробно на рис. 2 и 3.

Следует отметить, что содержание каждого элемента данной схемы определяется конкретной направленностью, отраслевой спецификой рассматриваемых проблем. Показательна в качестве примера в этом отношении работа [1], в которой рассмотрен процесс проектирования, учитывающий специфику кафедры «Лазерные и оптикоэлектронные системы» МГТУ им. Н.Э. Баумана. 


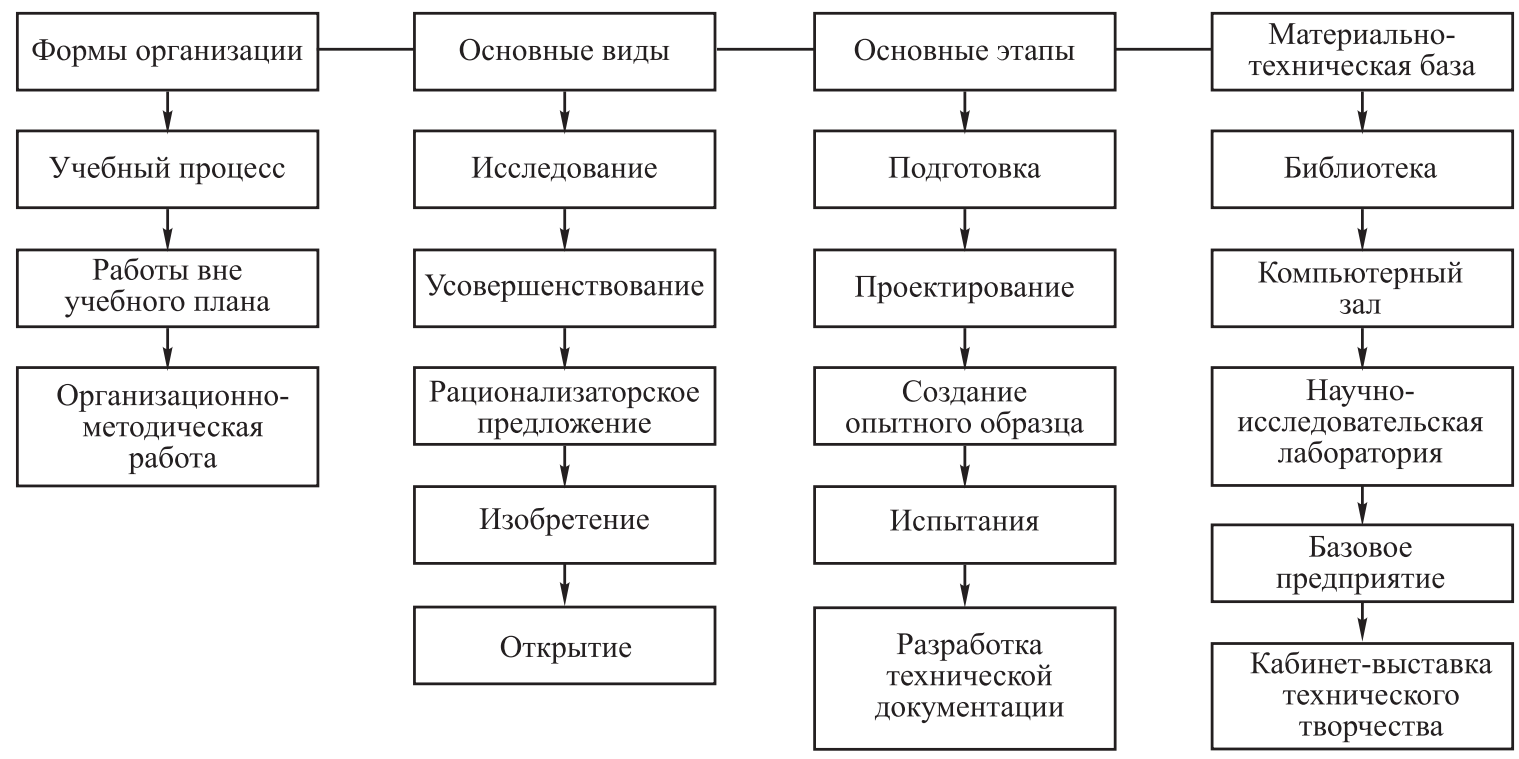

Puc. 1. Структура и формы организации технического творчества

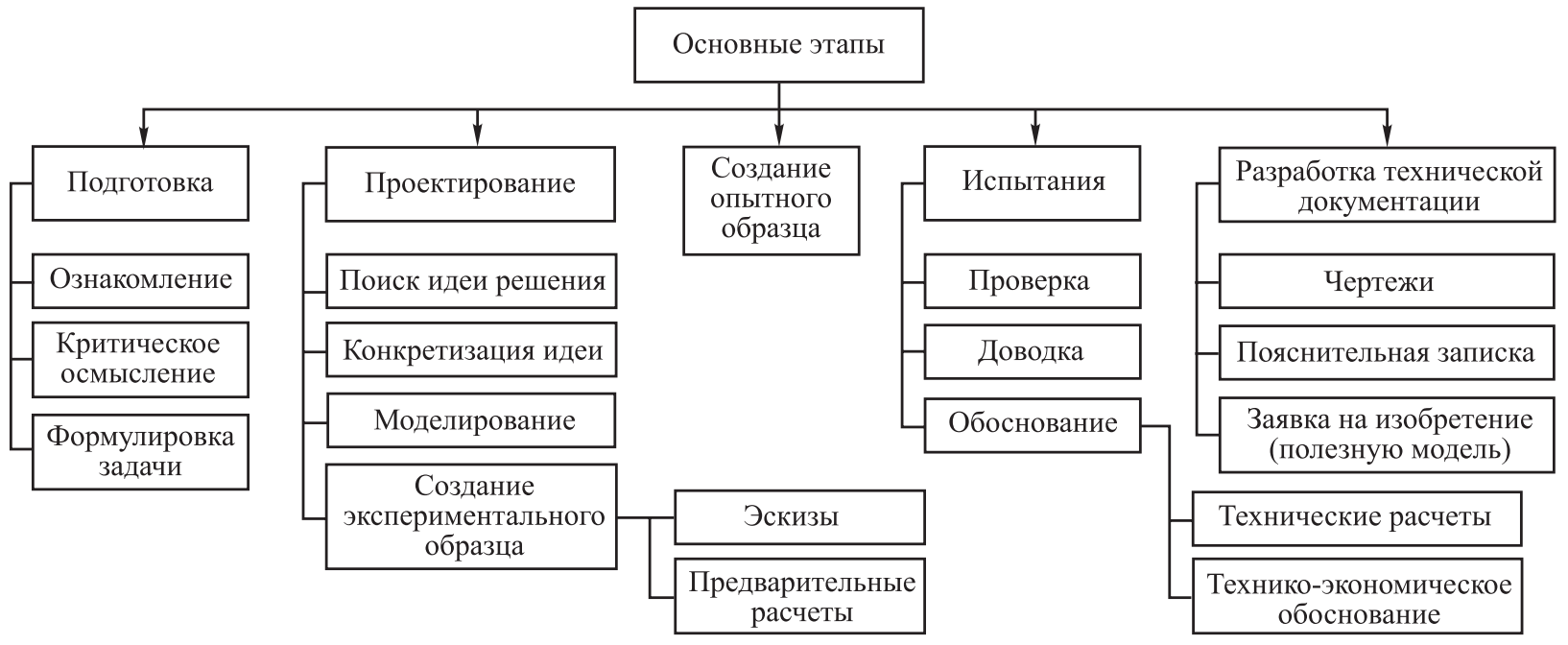

Puc. 2. Основные этапы технического творчества

Особый интерес при работе со студентами представляют формы организации технического творчества. Различные формы организации технического творчества подробно приведены на рис. 3. В частности, здесь рассмотрены наиболее значимые, на взгляд авторов, три направления: учебный процесс, работы вне учебного плана и организационно-методическая работа.

Таким образом, структура технического творчества и формы его организации отражают основные направления работы, выполняемые в техническом университете.

В приведенной структуре (см. рис. 1) техническое творчество и его формы организации связаны между собой и представляют единую, целостную систему. Рассмотреть содержание всех составных элементов даже в общем виде в рамках одной работы не представляется возможным. Поэтому остановимся лишь на отдельных звеньях организации технического творчества (см. рис. 3), в частности, рассмотрим некоторые аспекты методической работы по техническому творчеству и основные методы активизации технического творчества в отечественной и зарубежной практике.

В идеальном варианте методическая работа в техническом университете - это наличие методического фонда, как общего, в данном случае, факультетского, так и кафедрального с ориентацией на техническое творчество. В настоящее время многие преподаватели отмечают, что методических разработок, указаний и методик так много, что не нужно их разрабатывать, следует их собрать, систематизировать, продумать их 


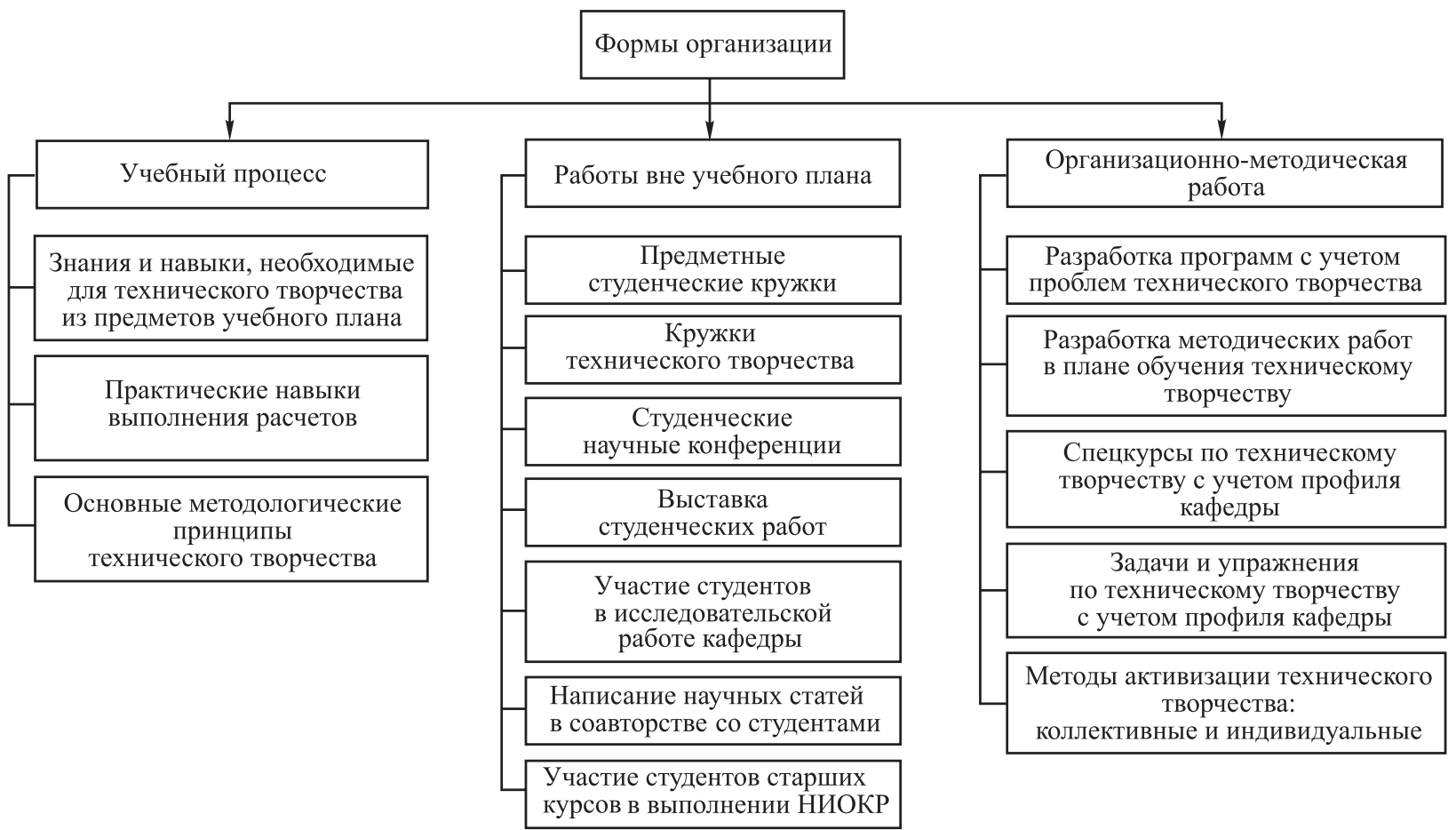

Puc. 3. Формы организации технического творчества

единство, взаимосвязь и взаимодействие. Однако это достаточно сложная работа и далека до своего завершения, хотя в МГТУ им. Н.Э. Баумана имеются интересные разработки в этом направлении [2, 3]. Более того, если такую систематизацию проводить, то следует учитывать многие факторы, например, междисциплинарный подход, который, несомненно, имеет творческий характер. Для реализации междисциплинарного подхода сначала нужно собрать обобщающий материал. Это сложная задача, как в организационном плане, так и в методическом. Более того, необходимо создание междисциплинарной методологии между различными техническими дисциплинами, разработка методических и учебных пособий, скоординированных между собой с позиций различных областей знания, с ориентацией на практическую деятельность. В этом случае учебные пособия принимают стройную логическую систему в соответствии с творческим подходом.

Важным моментом является также то, что блок междисциплинарных знаний следует расширять не только специальными техническими дисциплинами, но и другими и, в частности, следует уделять значительное внимание экологической проблематике, которая охватывает большинство инженерных специальностей. Как известно, по своей сути экология является интегрирующей наукой. Это целостная система знаний из различных областей, которая определяется структурой самой экологии. Понимание связи базируется не только на технических, но и на природных явлениях, их определенном соотношении. Экологическая безопасность чрезвычайно трудно внедряется в практику производственной деятельности. Для будущего инженера в условиях новой техники и технологий экологическая направленность имеет особую значимость.

С позиций междисциплинарного подхода разрабатываются и авторские программы, спецкурсы, которые должны охватывать новые тенденции в различных областях знаний, дополнять и расширять программу той или иной дисциплины. В таком варианте их творческий характер также очевиден.

Учебный процесс с междисциплинарной направленностью стимулирует студентов самостоятельно искать недостающую информацию, т. е. формирует навыки самообразования, что значительно расширяет их общий и профессиональный кругозор [4].

В раздел методической работы входят и методы активизации технического творчества. В России и за рубежом накоплен значительный опыт в этом направлении. Методы активизации технического творчества как отечественные, так и зарубежные разработаны изобретателямипрактиками на основе анализа большого пра- 
ктического материала и направлены на решение нестандартных задач.

В отечественной и зарубежной практике методы активизации различны. В зарубежных методиках все внимание сосредоточено на активизации психологических моментов творчества (ассоциации, аналогии и т. д.), при этом большое внимание уделяется преодолению психологической инерции. Пагубное влияние психологической инерции на творческий процесс осознано всеми и давно. Применение эвристических методов способствует снижению психологического барьера. Под психологической инерцией, в данном случае, понимают привычку к шаблонному мышлению, стремлению делать «как всегда, как все», и это действительно необходимо и оправдано. Однако при поиске нового решения психологическая инерция является серьезным препятствием, мешает нестандартному подходу, новому видению задачи с разных точек зрения. Поэтому не случайно для борьбы с психологической инерцией в зарубежных фирмах, работающих в инновационном направлении, ограничивают число специалистов с опытом работы, т. е. творческий коллектив формируют не только из профессионалов и опытных специалистов. Человек по своей природе экономен, он думает в привычном направлении, устойчивые знания ориентируют искать ответы в готовых решениях, ранее используемых, в результате получаются штампы, стандартные решения. Чтобы ослабить данную ситуацию, часто в творческую группу включают специалиста из другой сферы деятельности. Как показывает практика, это оправдано, так как он предлагает нестандартные решения, и получается как по известному афоризму: «Все знают, что это невозможно, но приходит один чудак, который этого не знает, и делает открытие», поэтому различные эвристические подходы при поиске новых решений просто необходимы.

Широкую популярность в мировой практике получил метод мозгового штурма (мозговая атака или конференция идей) - метод активизации творческой деятельности, разработанный американским психологом Алексом Осборном.

Мозговой штурм особенно эффективен в молодежной, студенческой аудитории, так как при его использовании не создается такого напряжения, которого требуют другие методы, помогает организовать поисковый коллектив, «растормозить» участников, избежать привычных и потому бесплодных ассоциаций, т. е. уменьшает психологическую инерцию, которая, как и в любой коллективной форме работы, как бы взаимно уничтожается. При этом студенты учатся спорить, высказывать свои мысли, воспринимать аргументы друг друга, допускаются шутки, парадоксы.

Метод мозгового штурма применяется, как правило, при поиске новых идей в условиях отсутствия необходимого объема информации, достаточного для проведения логического анализа. Существует множество разновидностей мозгового штурма, обусловленных особенностями человеческого мышления, спецификой решаемых задач. Однако всех их объединяют общие технологии для его проведения.

Осборн считал, что люди делятся на тех, кто генерирует идеи (преобладает творческое мышление) и аналитиков (доминирует критическое мышление). Разработка идеи включает два основных взаимосвязанных этапа, которые находятся в единстве, взаимно дополняют друг друга: 1) творческий этап, на котором происходит генерация, рождение новых идей; 2) критический (логический) этап, на котором осуществляется анализ, сравнение, оценка, заключение, вывод. Поэтому процесс поиска решения проблемы разбивается на два этапа, реализуемых в работе двух групп. Первая группа (генераторов) 7-9 человек ищет решение в свободном обсуждении, при условии запрета любой критики высказанных идей. Всем известно, что опасение критики тормозит процесс генерирования, выдвижения смелых идей и многие нестандартные положения могут быть невысказанными. В работе должна царить атмосфера оптимизма и вера в решение задач. Вторая группа участников 7-9 человек анализирует, уточняет, дорабатывает данные идеи.

Одной из модификаций метода мозгового штурма является обратный штурм, который не запрещает критику, как это принято в рассмотренном выше варианте мозгового штурма, а, наоборот, активизирует критические замечания, заставляет отыскивать как можно больше недостатков у конструкции, позволяет находить слабые места, т. е. проверяет обоснованность сгенерированных идей.

Один из вариантов метода мозгового штурма теневая мозговая атака, автором которого является отечественный разработчик А.Б. Попов. В этом варианте задействуется более 30 человек, и значительно изменяется форма участия в работе. А.Б. Попов предложил разделить участников на две группы, и расположить их за соседними столами. Если одна группа генерирует идеи, то другая (участники теневой атаки) - развивают их, углубляют, записывают свои соображения, предложения, критические замечания, не высказывая их вслух. Такой подход помогает 
преодолеть нерешительность, стеснительность многих участников. Качество выдвигаемых идей в данном методе значительно улучшается.

Разновидностью метода мозгового штурма является «кросс идей», разработанный немецкими учеными. Если в рассмотренных выше вариантах мозгового штурма нет состязательности - все идеи являются общими, то здесь автор выдвинутой интересной, результативной идеи поощряется и не подвергается критике за неудачные предложения. Число участников в «кроссе идей» меняется от 10 до 30 человек.

Интересной модификацией «кросса идей» является «эстафета идей». Здесь поиск идеи решения ведется участниками не индивидуально, а командами. В этом случае идеи внутри команды формируются совместно, а соревнование проходит между командами.

Следует отметить, что все разновидности мозгового штурма вполне успешно применяются и используются как для поиска и генерирования нестандартных задач, так и для их решения. Однако методом мозгового штурма успешно решаются относительно несложные задачи. Усилить мозговой штурм можно, используя методы, подсказывающие неожиданные сравнения, позволяющие взглянуть на объект под необычным углом. К ним относится метод фокальных объектов, предложенный профессором Берлинского университета Э. Кунце и в дальнейшем усовершенствованный американским ученым Ч. Вайтингом. Суть метода состоит в том, что техническую систему при поиске ее идеального варианта совершенствования рассматривают, примеряя свойства других технических систем, которые даже не связанны с исходной. При этом возникают необычные, интересные сочетания, которые стараются развить дальше путем свободных ассоциации. Как показывает практика, иногда рождаются новые, нестандартные идеи. Этот метод применяется также для развития творческого воображения, способствует приобретению навыков изобретательства.

В основе всех разновидностей мозгового штурма лежит общий принцип поиска решения задач - метод проб и ошибок, который также имеет множество модификаций. Это самый древний метод создания всех технических систем. История развития техники свидетельствует, что на ранних стадиях на основе метода проб и ошибок создавались все технические конструкции. Однако с усовершенствованием техники этот метод становился все менее пригодным, поскольку развитие науки позволяло уже искать наилучший вариант технических систем при помощи расчетов и целенаправленных исследований. Тем не менее, и в настоящее время значимость метода проб и ошибок в различных его модификациях еще достаточно велика в области творчества и изобретательства, при поиске принципиально новых идей и решений. Его значение нельзя абсолютизировать, а также недооценивать в поисковой творческой деятельности. Привлекательность этого метода состоит в том, что отсутствуют какие-либо ограничения: можно предлагать, выдвигать любые варианты и даже алогичные. Как правило, перебор вариантов поиска решений начинается со стандартных, традиционных вариантов, постепенно переходя к более смелым идеям. Если и в этом случае решение не найдено, то применяют различные методы систематизации перебора. Таким образом реализуется не хаотический бессистемный перебор вариантов, а целенаправленный поиск, что значительно сужает поле поиска. Следует отметить, эффективность перебора зависит также и от сложности задачи, что определяет количество проб, которые необходимо сделать, чтобы гарантированно получить результат. История изобретательства показывает, что количество вариантов перебора может колебаться - от десятка проб для самых простых задач и до более значительной величины для сложных. Метод проб и ошибок достаточно эффективен, когда поиск решения имеет до 20 вариантов, а при решении более сложных задач, его не следует применять, он не только неэффективен при решении сложных задач, но и затрудняет их постановку.

Поиск решений методом проб и ошибок без применения методов систематизации графически изображен на рис. 4, $a$.

Из исходной точки «задача», нужно прийти в точку «решение». Направленность поиска «решение» неизвестно, а правил отбора нет, приходится действовать либо интуитивно, либо наугад. Выбирают произвольное направление, делается одна попытка, другая, третья и т. д. Если решение задачи не находится, следует изменить «курс» и осуществлять новые попытки. Как правило, все попытки поиска сосредоточены в привычном, общепринятом, общеизвестном направлении. Такой подход получил название «вектор психологической инерции». Нестандартная, изобретательская задача потому и трудна, что ее решение осуществляется в новом, неожиданном, в нестандартном направлении. И здесь следует увеличить, расширить хаотичность поиска и изменить систематизацию перебора. Для этого применяют специальные психологические приемы, позволяющие избежать инерционной 


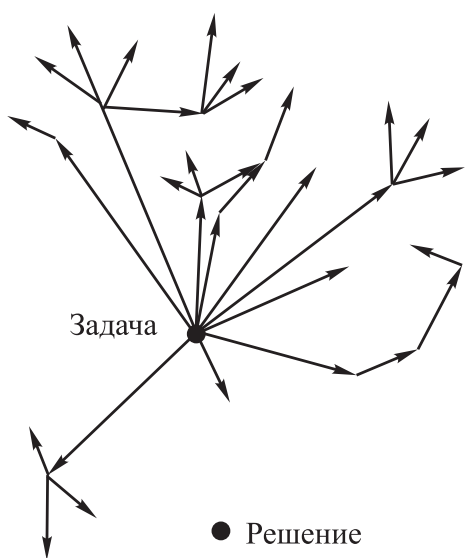

$a$

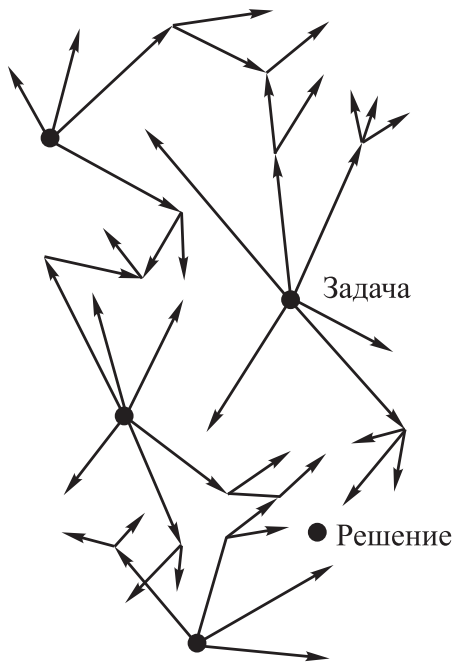

6

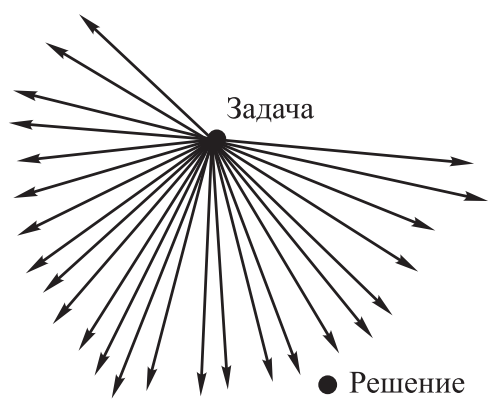

B

Puc. 4. Перебор вариантов решения:

$a-$ без применения методов систематизации; 6 - с применением простых форм систематизации; $8-$ с применением сложных форм систематизации

направленности поиска, которые основаны на введении элементов случайности, непредсказуемости поиска, активизирующие ассоциативные способности человека и увеличивающие число проб (рис. 4, б).

При усложнении форм систематизации перебора расширяется поле поиска, исключаются свойственные ненаправленному поиску повторы, постоянный возврат к одним и тем же идеям (рис. 4, в).

К методам систематизации перебора относятся морфологический анализ (Ф. Цвикки), многочисленные списки контрольных вопросов, среди которых наиболее удачными являются списки А. Осборна и Т. Эйлоарта.

Рассмотренные методы можно комбинировать, видоизменять. Они эффективны при решении несложных задач. Использование этих методов активизирует возможности фантазировать, интуицию, склонность к аналогиям, ассоциациям и др. Действительно, как показывает практика, именно решение изобретательских задач часто осуществляется в совсем неожиданном и новом направлении на основе данных методов.

Особый интерес в зарубежной практике представляет такая коллективная форма работы, как креативные группы. В отличие от рассмотренных выше коллективных методов активизации, креативные группы могут решать достаточно сложные задачи. Креативные группы нашли широкое применение во всех отраслях за рубежом [5]. В образовательном процессе их ценность заключается не только в эффективном решении тех или иных конкретных задач, но и в обучении, формировании практических навыков творческой деятельности [6]. Особое достоинство креативных групп заключается также и в том, что здесь могут продуктивно работать участники со средними, обыкновенными способностями. В отличие от индивидуального творчества креативная группа может решать далеко не все задачи, например, определенные задачи теоретического плана.

Методики организации и работы креативных групп широко представлены в зарубежной литературе. Наиболее удачной в этом плане является работа основателя этого направления [7], остальные технологии являются лишь различными модификациями основополагающих принципов. Более того методика, изложенная в работе [7], ориентирована на формы организации, работы в плане технического творчества, для решения практических, технических задач.

Методы активизации и организации творческой деятельности в зарубежной практике значительно отличаются от отечественных методов, которые в большинстве своем основаны на логическом подходе к решению технических задач. Отечественные практики считают, что в первую очередь следует опираться при генерировании идей не на психологические особенности разработчика, а на законы развития материальных технических систем. Знание закономерностей развития технических систем дает возможность резко сузить поле поиска, заменить «угадыва- 
ние» научным подходом. Данные методы наиболее сложны, здесь нет игровых вариаций, но в профессиональном плане подготовки, формирования практических навыков технического творчества они более эффективны [8].

Отечественные и зарубежные методы активизации технического творчества имеют как свои достоинства, так и недостатки. Например, генерировать нестандартные, новые технические идеи лучше позволяют зарубежные методы, а совершенствовать техническую систему - отечественные. В качестве рекомендации следует предложить использовать и те и другие в зависимости от сложности решаемой проблемы, ее специфики.

Таким образом, основная цель различных форм активизации творческой деятельности, формирование практических навыков технического творчества, подготовка студентов к самостоятельной работе. Другими словами, все направления и формы организации технического творчества направлены на подготовку будущих инженеров, способных с университетской скамьи сразу же включаться в процесс разработки современной техники

В заключение следует отметить, что творческий подход должен быть центральным при разработке, как методов преподавания, так и других форм работы со студентами. Стихийно эта работа не может осуществляться, требуется определенная координация и управление этими процессами.

\section{Литература}

[1] Гоев А.И., Заварзин В.И., Чичварин Н.В. Организация проектирования и производства оптико-электронных систем в среде с ограниченными ресурсами. Информационные технологии, 2001, № 7, с. 2-13.

[2] Дорофеев А.А. Учебная литература по инженерньм дисииплинам: системная дидактика, методика и практика проектирования. Москва, Изд-во МГТУ им. Н.Э. Баумана, 2012. $398 \mathrm{c}$.

[3] Потапцев И.С., Нарыкова Н.И., Перминова Е.А., Буцев А.А. Разработка конструкторской документации при курсовом проектировании. В 2 ч. Москва, Изд-во МГТУ им. Н.Э. Баумана, 2010. 78 с.

[4] Бушуева В.В., Бушуев Н.Н. Междисциплинарный подход и его значение при подготовке инженеров. Формирование профессиональной культуры специалистов ХХІ века в техническом университете. Сб. науч. тр. 12-й Междунар. науч.-практ. конф. Санкт-Петербург, Изд-во политехн. ун-та, 2012, с. 73-74.

[5] Бушуева В.В. Креативные группы в зарубежной практике. Наука и образование, 2012, № 6. URL: http://technomag.edu.ru/doc/419183.html (дата обращения 05 апреля 2014).

[6] Потапцев И.С., Бушуева В.В. Студенческие креативные группы и их значение в формировании навыков технического творчества. Наука и образование, 2012, № 3, URL: http://technomag.edu.ru/doc/419183.html (дата обращения 05 апреля 2014).

[7] Aznar G. La creativite dans l'ertrepise. Paris, Editions d'Organisation, 1971. 185 p.

[8] Ревенков А.В., Резчикова Е.В. Теория и практика решения технических задач. Москва, ФОРУМ, 2009. 384 c.

\section{References}

[1] Goev A.I., Zavarzin V.I., Chichvarin N.V. Organizatsiia proektirovaniia i proizvodstva optiko-elektronnykh sistem $\mathrm{v}$ srede s ogranichennymi resursami [Organization design and manufacture of optoelectronic systems in an environment with limited resources]. Informatsionnye tekhnologii [Information Technologies]. 2001, no. 7, pp. 2-13.

[2] Dorofeev A.A. Uchebnaia literatura po inzhenernym distsiplinam: sistemnaia didaktika, metodika $i$ praktika proektirovaniia [Educational literature on engineering: system didactics, methodology and practice of designing]. Moscow, Bauman Press, 2012. 398 p.

[3] Potaptsev I.S., Narykova N.I., Perminova E.A., Butsev A.A. Razrabotka konstruktorskoi dokumentatsii pri kursovom proektirovanii [Development of design documentation at course design]. Moscow, Bauman Press, 2010. 78 p.

[4] Bushueva V.V., Bushuev N.N. Mezhdistsiplinarnyi podkhod i ego znachenie pri podgotovke inzhenerov [Interdisciplinary approach and its importance in the training of engineers]. Formirovanie professional'noi kul'tury spetsialistov 21 veka $v$ tekhnicheskom universitete: Sbornik nauchnykh trudov 12-i Mezhdunarodnoi nauchno-prakticheskoi konferentsii [Formation of professional culture experts 21 century at the Technical University: Collection of scientific works of the 
$12^{\text {th }}$ International Scientific and Practical Conference]. St. Petersburg, St. Petersburg State Polytechnical University publ., 2012, pp. 73-74.

[5] Bushueva V.V. Kreativnye gruppy v zarubezhnoi praktike [Creative groups in foreign experience]. Nauka i obrazovanie: nauchno-tekhnicheskoe izdanie [Science and Education: Electronic Scientific and Technical Periodical]. 2012, no. 6. Available at: http://technomag.edu. ru/doc/419183.html (accessed 5 April 2014).

[6] Potaptsev I.S., Bushueva V.V. Studencheskie kreativnye gruppy i ikh znachenie v formirovanii navykov tekhnicheskogo tvorchestva [Student creative groups and their importance in shaping the skills and technical creativity]. Nauka i obrazovanie: nauchno-tekhnicheskoe izdanie [Science and Education: Electronic Scientific and Technical Periodical]. 2013, no. 3. Available at: http://technomag.bmstu.ru/doc/555888.html (accessed 5 April 2014).

[7] Aznar Cr. La creativite dans l'ertreprise [Creativity in business]. Paris, 1971. 185 p.

[8] Revenkov A.V., Rezchikova E.V. Teoriia i praktika resheniia tekhnicheskikh zadach [Theory and practice of technical problems]. Moscow, FORUM publ., 2009. 384 p.

Статья поступила в редакцию 05.05.2014

\section{Информация об авторах}

ПОТАПЦЕВ Игорь Степанович (Москва) - кандидат технических наук, доцент кафедры «Элементы приборных устройств». МГТУ им. Н.Э. Баумана (105005, Москва, Российская Федерация, 2-я Бауманская ул., д. 5, стр. 1, e-mail: isp1939@mail.ru).

БУШУЕВА Валентина Викторовна (Москва) - кандидат философских наук, доцент кафедры «Философия». МГТУ им. Н.Э. Баумана (105005, Москва, Российская Федерация, 2-я Бауманская ул., д. 5, стр. 1, e-mail: vbysh2008@rambler.ru).

БУШУЕВ Николай Николаевич (Москва) - кандидат биологических наук, доцент кафедры «Экология и промышленная безопасность». МГТУ им. Н.Э. Баумана (105005, Москва, Российская Федерация, 2-я Бауманская ул., д. 5, стр. 1, e-mail: agrohim1@rambler.ru).

\section{Information about the authors}

POTAPTSEV Igor' Stepanovich (Moscow) - Cand. Sc. (Eng.), Associate Professor of «Elements of Instrument Devices» Department. Bauman Moscow State Technical University (BMSTU, building 1, 2-nd Baumanskaya str., 5, 105005, Moscow, Russian Federation, e-mail: isp1939@mail.ru).

BUSHUEVA Valentina Viktorovna (Moscow) - Cand. Sc. (Phyl.), Associate Professor of «Philosophy» Department. Bauman Moscow State Technical University (BMSTU, building 1, 2-nd Baumanskaya str., 5, 105005, Moscow, Russian Federation, e-mail: vbysh2008@rambler.ru).

BUSHUEV Nikolay Nikolaevich (Moscow) - Cand. Sc. (Biol.), Associate Professor of «Ecology and Industrial Safety» Department. Bauman Moscow State Technical University (BMSTU, building 1, 2-nd Baumanskaya str., 5, 105005, Moscow, Russian Federation, e-mail: agrohim1@rambler.ru). 